\title{
Obesity: Implications for Women's Reproductive Health
}

\author{
Jeanette R. Chin • Maureen A. Murtaugh • Robert Silver
}

Published online: 16 January 2014

(C) Springer International Publishing AG 2014

\begin{abstract}
Obesity is an epidemic in the developed world. In the U.S., over one-third of women are now obese, with significant adverse consequences for their reproductive and longterm health. Many of these women gain excessive weight in pregnancy and retain it postpartum, with an additive effect across multiple pregnancies. Maternal obesity is associated with an increased risk for miscarriage, congenital anomalies, stillbirth, gestational diabetes, preeclampsia, and cesarean section. Offspring of obese women are at increased risk for being large for gestational age and may be programmed for obesity and metabolic syndrome, thus perpetuating a cycle of obesity across generations. Certain alterations to routine prenatal care may be necessary for obese women in order to optimize obstetric and neonatal outcomes. Future research priorities should be aimed at understanding the biologic mechanisms underlying the adverse outcomes associated with maternal obesity and at developing effective interventions for this growing high-risk population.
\end{abstract}

Keywords Obesity · Pregnancy outcomes · BMI · Gestational weight gain · Reproduction · Miscarriage $\cdot$ Cesarean section · Gestational diabetes $\cdot$ Preeclampsia $\cdot$ Preterm birth .

Congenital anomalies $\cdot$ Fetal programming

J. R. Chin $(\bowtie) \cdot$ R. Silver

Division of Maternal-Fetal Medicine, Department of Obstetrics and Gynecology, University of Utah, 30 N. 1900 E. Room 2B200 SOM, Salt Lake City, UT 84132, USA

e-mail: jeanette.chin@hsc.utah.edu

R. Silver

e-mail: bob.silver@hsc.utah.edu

\section{A. Murtaugh}

Division of Epidemiology, Department of Internal Medicine,

University of Utah, 295 Chipeta Way, Room 1 N402,

Salt Lake City, UT 84108, USA

e-mail: maureen.murtaugh@hsc.utah.edu

\section{Introduction}

Obesity is arguably the most pressing health concern in the developed world. Nearly $35 \%$ of adults 20 years and older in the United States are obese [1•]. A 2005 analysis indicated that over the next several decades, there may be a sustained drop in life expectancy for Americans related to the obesity epidemic [2]. In 2011/2012, 36.1\% of women 20 years and older were obese (body mass index [BMI] $\geq 30 \mathrm{~kg} / \mathrm{m} 2$ ) [1•], with nonHispanic black women (of whom $56.6 \%$ are obese), most profoundly affected. Obesity is associated with a wide range of adverse outcomes throughout a woman's reproductive life. Obese women are at increased risk for pregnancy loss, preeclampsia, gestational diabetes (GDM), and cesarean delivery [3-5]. Offspring of obese women are at greater risk of anomalies, stillbirth, and being large for gestational age (LGA) $[3,6$, 7]. Although these immediate pregnancy outcomes are of great concern, the long-term impacts of maternal obesity are potentially even worse, and are becoming increasingly apparent. Through epigenetic mechanisms, the offspring of obese women may be programmed for obesity and metabolic syndrome later in life, thereby propagating the issue across generations.

BMI is the most commonly utilized parameter to define obesity. The National Institutes of Health $(\mathrm{NIH})$ and the World Health Organization (WHO) define underweight, normal weight, overweight, and obese as a BMI of $<18.5,18.5-24.9$, $25.0-29.9$, and $\geq 30 \mathrm{~kg} / \mathrm{m}^{2}$, respectively. Obesity is further stratified as class I (BMI 30-34.9), class II (BMI 35-39.9), and class III (BMI $\geq 40$ ). There are obvious limitations to the use of BMI later in pregnancy, when a woman's gestational weight gain (GWG) is comprised not only of increased adipose mass but other factors, including water, amniotic fluid, placenta, and fetal weight. For this reason, studies of maternal obesity most commonly utilize a BMI calculated from a self-reported prepregnancy weight and height. Such self-reported variables are subject to bias, as women tend to underreport their pre- 
pregnancy weight and over-report GWG [8]. Unfortunately, even the most robust national data sources on maternal BMI and GWG, such as the Pregnancy Risk Assessment Monitoring System (PRAMS) and Pregnancy Nutrition Surveillance System (PNSS), use recalled weight values.

It is important to separate the independent effects of prepregnancy BMI and GWG on adverse pregnancy outcomes. Indeed, the relationship between GWG and adverse outcomes is modified by a woman's pre-pregnancy BMI $[9,10]$. In 2009, the Institute of Medicine (IOM) released revised GWG guidelines based on pre-pregnancy BMI [11]. For obese women, the previous recommendation of GWG of at least 15 pounds was changed to a specific, fairly narrow range of 11-20 pounds. There were insufficient data to provide recommendations specifically for women in any obesity class higher than class I.

Despite the recommended 11-20 pound GWG for obese women, studies suggest that little to no GWG may be beneficial to obese women in terms of optimizing several obstetric outcomes $[12,13 \bullet]$. Kominiarek et al. found that the lowest average predicted probability of composite adverse outcome (cesarean, postpartum hemorrhage, SGA, LGA, or neonatal intensive care admission) actually occurred when obese women lost weight during pregnancy [13•]. Excessive GWG is a common occurrence among all women [14] and is associated with increased risk of an LGA infant, GDM, and cesarean delivery $[9,15]$. Women who gain excessive weight appear more likely to retain the weight postpartum [16]. However, the association between parity, GWG, and risk for later obesity is complex, subject to many potential confounders, and may vary with the subgroup of women studied. Cohen et al., using a life course approach, found that the prevalence of midlife (age 40-41) obesity increases with a rising number of excessive GWG events, regardless of parity [17]. Another study focusing on women in later life (66-102 years) found a doseresponse relationship between number of children and obesity [18]. After controlling for potential confounders, the risk of obesity increased $11 \%$ with each live birth. In contrast, a recent study examining over 2,700 contemporary women in their late 20 s and early 30 s found that childbearing was not related to incidence of obesity [19]. It has been suggested that women who gain excessive weight during pregnancy and retain it postpartum may have gained a similar amount of weight over time, even without childbearing, related to population trends and underlying factors such as race/ethnicity, aging, and socioeconomic status [19].

The current obesity epidemic among women, therefore, is not entirely attributable to excessive GWG and childbearing. However, a healthy diet and moderate physical activity in pregnancy should be encouraged, as observational data indicate that these factors are associated with decreased risk of excessive GWG [20]. Although some tested interventions have proven effective at helping women reduce GWG, there have been no consistently positive effects on maternal and neonatal outcomes in these studies [21]. It is also reasonable to consider referring obese women to a dietician early in pregnancy.

Retained postpartum weight has a negative impact on subsequent pregnancies. There is a linear relationship between weight retention after a first pregnancy and increased risk in subsequent pregnancies for hypertensive disorders, GDM, cesarean delivery, stillbirth, and an LGA infant [22]. Excessive GWG in the first pregnancy therefore presents a window of opportunity for intervention in terms of postpartum weight retention and subsequent pregnancies. This is particularly important as women who gain excessive weight in one pregnancy often repeat the pattern in a subsequent pregnancy [23].

Table 1 details the risk of a range of adverse pregnancy outcomes among obese women. Table 2 presents recommendations for alterations to routine prenatal care for obese women.

\section{Fertility and Pregnancy Loss}

Obesity is associated with subfertility and increased risk of pregnancy loss. This subfertility is linked to oligoovulation and polycystic ovarian syndrome, which frequently co-occur with obesity. In a prospective study of 1,651 women attempting pregnancy, there was a dose-response relationship between increasing BMI category and decreasing fecundability ratio

Table 1 Risk of selected adverse obstetric outcomes for obese women $\left(\mathrm{BMI} \geq 30 \mathrm{~kg} / \mathrm{m}^{2}\right.$ ) vs. normal-weight women $\left(\mathrm{BMI}<25 \mathrm{~kg} / \mathrm{m}^{2}\right.$ )

\begin{tabular}{|c|c|}
\hline Outcome & $\begin{array}{l}\text { Odds Ratio (OR) or Relative Risk } \\
\text { (RR) (95\% Confidence Interval) }\end{array}$ \\
\hline $\begin{array}{l}\text { Pregnancy loss (spontaneous or } \\
\text { assisted conception) [4] }\end{array}$ & OR $1.89(1.14-3.13)$ \\
\hline Stillbirth [89] & OR $1.72(1.22-2.43)$ \\
\hline Neural tube defects [33] & OR $1.9^{\mathrm{a}}(1.3-2.9)$ \\
\hline Gestational diabetes [3] & OR $2.6(2.1-3.4)$ \\
\hline Preeclampsia [3] & OR $1.6(1.1-2.3)$ \\
\hline \multicolumn{2}{|l|}{ Indicated preterm birth [44] } \\
\hline • 22-27 weeks & OR $2.48(1.99-3.1)$ \\
\hline -28-31 weeks & OR $1.91(1.68-2.17)$ \\
\hline • 32-36 weeks & OR $1.62(1.54-1.71)$ \\
\hline Large-for-gestational age infant ${ }^{\mathrm{b}}[10]$ & OR $2.9(2.7-3.2)$ \\
\hline Cesarean section [62] & RR 1.96 (1.84-2.09) \\
\hline \multicolumn{2}{|l|}{$\begin{array}{l}\text { Post-operative infectious morbidity } \\
\text { (endometritis, wound infection, } \\
\text { urinary tract infection, septic } \\
\text { pelvic thrombophlebitis, } \\
\text { pneumonia) }\end{array}$} \\
\hline - Elective cesarean & RR $1.6(1.2-2.0)$ \\
\hline - Non-elective cesarean & RR $3.0(1.6-5.8)$ \\
\hline
\end{tabular}

BMI, body mass index

${ }^{\text {a }}$ Comparison for women with a BMI $>29 \mathrm{~kg} / \mathrm{m}^{2}$ vs. BMI $\leq 29 \mathrm{~kg} / \mathrm{m}^{2}$

${ }^{\mathrm{b}}$ Risk for an LGA infant among obese women varies with gestational weight gain. Absolute increase in risk from low to very high gestational weight gain $(<10 \mathrm{~kg}$ to $\geq 20 \mathrm{~kg})$ is $10-12 \%$ (10) 
Table 2 Suggested modifications to obstetric management for obese women

For all obese women of reproductive age:

- Provide preconception counseling at routine medical or gynecologic visits regarding the risks of obesity in pregnancy.

- Advise weight loss prior to pursuing pregnancy and discuss effective contraceptive methods. May consider referral for bariatric surgery.

\begin{tabular}{|c|c|}
\hline omplication & Recommended management \\
\hline Excessive GWG & $\begin{array}{l}\text { - Counsel on IOM GWG guidelines, diet and } \\
\text { physical activity, and postpartum weight } \\
\text { retention. } \\
\text { - Consider referral to a dietician. }\end{array}$ \\
\hline Preeclampsia & $\begin{array}{l}\text { Consider baseline } 24 \text {-hour urine collection for } \\
\text { protein in patients with chronic } \\
\text { hypertension, } \\
\text { renal disease, or other risk factors for } \\
\text { preeclampsia (i.e., pre-gestational diabetes) }\end{array}$ \\
\hline $\begin{array}{l}\text { Gestational } \\
\text { diabetes } \\
(\text { GDM })\end{array}$ & $\begin{array}{l}\text { - Assessment for pre-gestational glucose } \\
\text { intolerance or diabetes with an early glucose } \\
\text { tolerance test (repeated at } 24-28 \text { weeks if } \\
\text { normal), random or fasting blood glucose, or } \\
\text { hemoglobin A1c } \\
\text { - Postpartum glucose tolerance test for women } \\
\text { with GDM }\end{array}$ \\
\hline Stillbirth & $\begin{array}{l}\text { Consider non-stress tests and assessment of } \\
\text { amniotic fluid volume in the 3rd trimester, } \\
\text { particularly in the presence of additional risk } \\
\text { factors such as diabetes, hypertension, or } \\
\text { advanced maternal age. }\end{array}$ \\
\hline $\begin{array}{l}\text { Prolonged 1st } \\
\text { stage of labor }\end{array}$ & $\begin{array}{l}\text { In the setting of a reassuring fetal heart rate } \\
\text { tracing, allow additional time to progress in } \\
\text { the } 1 \text { st stage of labor prior to proceeding } \\
\text { with cesarean. }\end{array}$ \\
\hline $\begin{array}{l}\text { Large-for- } \\
\text { gestational } \\
\text { age infant }\end{array}$ & $\begin{array}{l}\text { Consider ultrasonographic assessment of fetal } \\
\text { weight in the } 3 \text { rd trimester if accurate fundal } \\
\text { heights are not obtainable. }\end{array}$ \\
\hline Thromboembolism & $\begin{array}{l}\text { - Perioperative mechanical } \\
\text { thromboprophylaxis } \\
\text { - Consideration of perioperative } \\
\text { pharmacologic thromboprophylaxis, } \\
\text { particularly with risk factors in addition to } \\
\text { obesity (e.g. diabetes, emergent delivery) }\end{array}$ \\
\hline $\begin{array}{l}\text { - Post-partum } \\
\text { weight retention } \\
\text { - Future risks of } \\
\text { disease }\end{array}$ & $\begin{array}{l}\text { - Counsel regarding postpartum weight loss } \\
\text { and lifestyle modification. } \\
\text { - Discuss future health risks based on pregnancy } \\
\text { complications (e.g., preeclampsia and } \\
\text { cardiovascular disease, GDM, and type } 2 \\
\text { diabetes). } \\
\text { - Discuss the need for long-term primary care } \\
\text { follow-up. }\end{array}$ \\
\hline
\end{tabular}

(FR) when compared to normal-weight women (FR $0.83,95 \%$ CI, 0.7-1.0; FR 0.75, $95 \%$ CI, 0.58-0.97; and FR 0.61, $95 \%$ CI, $0.42-0.88$ for overweight, obese, and very obese women, respectively) [24].

In a meta-analysis of studies examining the relationship between BMI and early pregnancy loss, women with a BMI $\geq 25$ had a higher likelihood of pregnancy loss, regardless of the method of conception, with an odds ratio (OR) of 1.67 (95\% CI, 1.25-2.25), when compared to normal-weight women [4]. The association persists even for women without pregestational diabetes (a known risk factor for pregnancy loss) [4]. Although approximately two-thirds of early pregnancy losses in the general population are related to aneuploidy, there appear to be other contributing mechanisms among obese women. In a retrospective case-control study of 204 pregnancy losses, Landres et al. found a $59 \%$ overall rate of aneuploidy, but that normal-weight women had a significantly greater number of aneuploid losses as compared to overweight and obese women (52.9\% vs. $36.6 \%)$ of similar age (34 years) [25].

Studies suggest that both decreased oocyte quality and decreased endometrial receptivity may contribute to pregnancy loss among obese women. The maturing oocyte and preimplantation embryo are sensitive to metabolic alterations, such as hyperinsulinemia [26]. Endometrial receptivity may be affected by the chronic inflammatory state of obesity and/or alterations in signaling of certain adipokines such as leptin and adiponectin [27]. While it is well-established that obese women undergoing IVF using autologous oocytes have decreased success (lower clinical pregnancy, lower live birth rates, and higher rates of pregnancy loss) [28], data are conflicting regarding outcomes of IVF cycles in obese women using donor oocytes $[29,30 \bullet, 31 \bullet \cdot]$. A meta-analysis concluded that obesity does not decrease the chances of pregnancy after in vitro fertilization (IVF) in donor oocyte recipients [30•]. However, a recent study, not included in that meta-analysis, among 9,587 first IVF cycles using oocyte donation from normal-weight women reported that implantation, pregnancy, clinical pregnancy, and rate of live births significantly decreased as the recipient's BMI increased, suggesting an endometrial defect $[31 \bullet \cdot$.

Obese women seeking to become pregnant, either through natural or assisted reproductive methods, should be counseled regarding the range of potential adverse outcomes across gestation and encouraged to lose weight prior to pursuing pregnancy.

\section{Congenital Anomalies}

Obese women are at significantly increased - albeit low absolute - risk for a range of fetal anomalies, including neural tube defects (NTDs), cardiac anomalies, anorectal atresia, hydrocephaly, limb reduction anomalies, and cleft lip/palate [7]. These risks appear to be independent of pregestational diabetes [7]. The association between obesity and NTDs has persisted even after fortification of the U.S. grain supply with folic acid was initiated in the late 1990s [32], and several studies have found the association between obesity and NTDs to be independent of folic acid intake in diet and/or supplements [33, 34].

Unfortunately, although obese women are at greater risk for fetal anomalies, the ability to detect these anomalies by ultrasound is limited $[35,36]$. Women must be counseled that 
some components of fetal anatomy may not be satisfactorily assessed at any point during gestation. However, sonographic fetal biometry is usually more accurate than fundal height measurement in women with a large abdominal panniculus.

\section{Gestational Diabetes}

Just as obesity outside of pregnancy is associated with type 2 diabetes, obesity in pregnancy increases the risk for gestational diabetes mellitus, or GDM (defined as diabetes diagnosed in pregnancy). In a study of over 16,000 women, obesity and morbid obesity were associated with odds ratios $(95 \%$ confidence interval) for GDM of $2.6(2.1-3.4)$ and 4.0 (3.1-5.2), respectively. Many obese women have pregestational glucose intolerance, and some may have undiagnosed pregestational diabetes. Consideration should be given to screening obese women (and particularly those with a history of GDM) early in pregnancy for pre-existing diabetes, using fingerstick assessment of random glucose, fasting blood glucose, or hemoglobin A1c. Women who develop GDM should be counseled that they are at significant risk for developing type 2 diabetes later in life [37] and need ongoing primary care follow-up and encouragement to institute healthy lifestyle changes.

\section{Preeclampsia}

Obesity in pregnancy is also associated with an increased risk for development of preeclampsia [3], defined by new-onset hypertension and proteinuria after 20 weeks gestation. Although this increased risk, in some cases, is related to underlying chronic hypertension and/or renal disease, obesity remains an independent risk factor [38]. Preeclampsia is associated with multiple complications, including placental abruption, preterm delivery, eclamptic seizure, and stroke. The underlying mechanisms by which obesity increases the risk for preeclampsia are not well understood. Chronic subclinical inflammation and endothelial activation may play a role. Insulin resistance may also be an important contributor to the development of preeclampsia. In a study of over 10,000 nulliparous women, a HOMA-IR (homeostasis model assessment of insulin resistance) result at $\geq 75$ th percentile was associated with nearly twice the risk (OR 1.9, $95 \% \mathrm{CI}, 1.1-3.2$ ) of developing preeclampsia compared to a HOMA-IR result at $<75$ th precentile [39]. The association persisted even after adjusting for BMI, race/ethnicity, treatment group, baseline blood pressure, and gestational age at sampling.

Recent attention has focused on the role that dyslipidemia may play in the development of preeclampsia, and statin drugs as potential preventive agents for high-risk women. Studies using animal models indicate that statins prevent the elevation in circulating antiangiogenic factors and vascular dysfunction characteristic of preeclampsia [40, 41]. Although statins are FDA category $\mathrm{X}$ (risks of use in pregnancy felt to clearly outweigh potential benefits), observational data suggest that they are actually not major teratogens [42] and their use in the prevention of preeclampsia is an active area of investigation.

Similar to the relationship between GDM and type 2 diabetes, women who are preeclamptic are at increased risk to develop cardiovascular or cerebrovascular disease later in life [43•].

\section{Preterm Birth}

When studying the relationship between obesity and preterm birth, it is important to distinguish between medically indicated (e.g., due to preeclampsia) and spontaneous (e.g., preterm labor or premature rupture of membranes) preterm birth. This is because medical conditions associated with obesity, such as chronic hypertension and diabetes, are themselves associated with increased risk for indicated preterm birth (due to concern regarding maternal and/or fetal risk of continuing the pregnancy).

In a recent analysis of nearly 1.6 million deliveries recorded in the Swedish Medical Birth Register, there was a doseresponse relationship between increasing maternal BMI and extremely preterm delivery (22-27 weeks gestation) [44・•]. As compared to normal-weight women, women with a BMI of 25-30 had an adjusted OR ( $95 \% \mathrm{CI})$ for extremely preterm delivery (indicated or spontaneous) of 1.26 (1.15-1.37). For women with a BMI $>40$, the OR for extremely preterm delivery was 2.99 (2.28-3.92). The risk of a medically indicated preterm birth at any gestational age increased accordingly with BMI for both overweight and obese women. When women with obesity-related disorders were excluded, the number of medically indicated preterm deliveries at 22 31 weeks was reduced by $60 \%$. An association between obesity and spontaneous preterm delivery was largely limited to women with higher grades of obesity and extremely preterm delivery (22-27 weeks).

In contrast to medically indicated preterm delivery, the data have not been consistent with regard to an association between obesity and spontaneous preterm birth. Ehrenberg et al. found that among women at increased risk for spontaneous preterm birth, those with a BMI $>25$ were actually at decreased risk of preterm birth at 22-24 weeks (OR 0.36, 95\% CI, 0.15-0.87) compared to women with a BMI $\leq 25$ [45]. There was a similar, although clinically insignificant, trend for preterm birth at 27-28 and 31-32 weeks.

In a secondary analysis of the Maternal-Fetal Medicine Units Network Preterm Prediction Study, obese women were found to have significantly fewer spontaneous preterm births $<37$ weeks $(6.2 \%$ vs. $11.2 \%, \mathrm{p}<0.001)$ and $<34$ weeks ( $1.5 \%$ vs. $3.5 \%, p=0.012)$, even after adjusting for age, parity, education, history of spontaneous preterm birth, black race, bacterial vaginosis, positive fetal fibronectin, and midtrimester cervical length [46]. Obese women also had a lower incidence of cervical length $<25 \mathrm{~mm}(5 \%$ vs. $8 \%$, p $=0.012)$ 
In conclusion, although obesity is consistently associated with increased risk of medically indicated preterm birth, the association between obesity and spontaneous preterm birth may be contingent on the subpopulation studied, severity of prematurity, and degree of obesity.

\section{Sleep Apnea}

Obesity is a major risk factor for obstructive sleep apnea. In the general adult population, sleep apnea is associated with increased mortality, cardiovascular disease, and stroke [47-49]. Emerging evidence suggests that sleep apnea may be an important contributor to adverse pregnancy outcomes, including pregnancy-induced hypertension, gestational diabetes, and impaired fetal growth $[50,51 \bullet]$. However, the study of sleep apnea in pregnancy has been challenging, in part because the sleep apnea screening tools commonly used in non-pregnant patients are not necessarily accurate for use in pregnancy [52].

The presence of sleep apnea may be an additional complicating factor when administering anesthesia to obese women. Obese women are already at greater risk of epidural/spinal block failure or multiple placement attempts and difficult intubation if general anesthesia is required [53]. Certain obese women at highest risk may benefit from antenatal anesthesia consultation.

\section{Peripartum Risks}

Obese women are at greater risk for a myriad of complications surrounding delivery, including cesarean delivery, oxytocin augmentation, postpartum hemorrhage, and post-term pregnancy [5, 54-60]. Multiple studies confirm a dose-response relationship between BMI and risk for cesarean delivery, particularly for the indication of "failure to progress" [56, 57, 61]. In one study, for each $1 \mathrm{~kg} / \mathrm{m}^{2}$ increase in maternal BMI, the risk for cesarean in labor increased by $5 \%$ for both nulliparous and multiparous women with no prior cesarean [62••]. Progress for obese women appears to be particularly slow during the latent phase of the first stage of labor [63]. The Consortium on Safe Labor constructed modern labor curves for nearly 119,000 women with term singleton gestations and found no apparent inflection point for nulliparous women entering the active phase of labor, but women with a BMI $>40$ took 1.2 hours longer to reach $10 \mathrm{~cm}$ dilation than those with a BMI $<25$ [64••]. For multiparous patients, there was an inflection point around $6 \mathrm{~cm}$, but it took 3.4 hours for women with a BMI $\geq 40$ to reach $6 \mathrm{~cm}$, as compared to 2.4 hours for those with a BMI $<25$. Obese women are also much less likely to succeed at a trial of labor after cesarean delivery. In one study, obese women with one prior cesarean had a trial-of-labor success rate of $68 \%$, compared to $79.6 \%$ for non-obese women [65].

The underlying mechanisms contributing to these labor abnormalities are not well understood, but myometrial contractility has been proposed as a potential cause. One study found that contractions were less forceful and frequent in myometrial strips obtained from obese women at the time of cesarean section compared to those from normal-weight women [66]. However, a later study did not confirm these findings [67]. Chiossi et al. reported that BMI does not affect the in vitro response of myometrial contractility to tocolytics [68]. However, other in vitro studies noted that myometrial contractility was impaired by LDL cholesterol and the adipokines apelin [69] and leptin [70].

Clinically, the objective assessment of uterine contraction strength is performed with intrauterine pressure catheters and the calculation of Montevideo units. Two studies found no difference between obese and normal-weight women in terms of Montevideo units achieved in labor [71, 72]. Therefore, while multiple studies have confirmed that obese women are at increased risk for a prolonged first stage of labor, this may be related not to impaired strength of uterine contractions, but rather difficulty in the contractions translating to cervical change.

Unfortunately, not only are obese women more likely to require cesarean delivery, but they are also at greater risk for wound infection, longer operative time, endometritis, and excessive blood loss when compared to normal-weight women $[73,74]$. Obesity compounds the risk of venous thromboembolism associated with pregnancy and the postoperative state. Although there are insufficient high-quality data to guide recommendations for thromboprophylaxis after cesarean delivery, in accordance with American College of Chest Physicians (ACCP) recommendations [75], consideration should be given to pharmacologic thromboprophylaxis for women with more than two additional risk factors for thromboembolism, which includes obesity.

It remains controversial as to whether a transverse or vertical skin incision is superior for obese women [76, 77]. No randomized trials of skin incision types have been conducted in obese women. The delivering provider should be aware that surgical landmarks such as the umbilicus may be significantly displaced in obese women, and choice of incision may affect both the type of uterine incision and ease of delivery.

\section{Bariatric Surgery}

The number of bariatric surgeries (malabsorptive and restrictive) performed in the U.S. has risen dramatically over the last several decades. More than $80 \%$ of bariatric surgeries are performed on women, half of whom are of reproductive age [78]. Ideally, women should delay pregnancy for 12 months after bariatric surgery (the period of most rapid weight loss). Women who have previously been oligo-ovulatory related to their obesity often begin to ovulate more regularly as they lose weight. Providers should be proactive in preparing women for this change in fertility and should recommend effective contraceptive methods for at least 12 months post-surgery. 
Studies indicate that bariatric surgery is associated with decreased risk of GDM, preeclampsia, and LGA infants [79•, 80-82], but an increased risk of anemia and SGA infants [79•, $82,83]$. Certain alterations to routine prenatal care are required for pregnant women with a history of bariatric surgery. They should be assessed regularly for nutritional deficiencies (vitamin B12, folic acid, iron, vitamin D, and calcium) and supplemented as indicated. Women who have undergone a malabsorptive procedure may have "dumping syndrome." For these women, the 50 gm glucose screen for GDM may cause fluid accumulation in the small intestine, with nausea, vomiting, diarrhea, and cramping. An alternative screening method recommended by the American Congress of Obstetrics and Gynecology is to have these women record fasting and postprandial fingerstick blood glucose for one week in both the second and third trimesters [84]. Additionally, ultrasonographic assessment of fetal growth in the third trimester in women who have had bariatric surgery is reasonable given the higher risk for SGA infants.

Clinicians should be attentive to gastrointestinal complaints and abdominal pain in pregnant women who have undergone bariatric surgery due to reported serious complications such as bowel obstruction, anastomotic leaks, hernias, and gastric rupture or band migration [85-87]. Women with gastric banding may require removal of fluid from the band to relieve nausea and vomiting or to achieve adequate nutritional intake. In such cases, consultation with a bariatric surgeon is indicated.

\section{Stillbirth}

Maternal obesity is a significant risk factor for stillbirth (defined as intrauterine fetal demise after 20 weeks gestation), particularly at later gestational ages $[6,54,88]$. A study from the Danish National Birth Cohort found that a BMI $\geq 30$ was associated with a hazard ratio for fetal death of $3.5(95 \% \mathrm{CI}$, $1.9-6.4)$ at 37-39 weeks and $4.6(95 \% \mathrm{CI}, 1.6-13.4)$ at $>40$ weeks, as compared to normal-weight women [6]. A recent analysis from the Stillbirth Collaborative Research Network including 614 stillbirth cases and 1,816 live birth controls found that overweight/obese status was independently associated with stillbirth, with an adjusted OR of 1.72 (95\% CI, 1.22-2.43) [89••]. The mechanisms by which obesity increases the risk for stillbirth are unknown, as the risk persists even after adjusting for confounding factors such as diabetes and preeclampsia [6]. Placental pathology and dysfunction may be important contributors. Obesity is associated with increased placental macrophage accumulation and inflammation $[90 \bullet, 91]$. Data indicate that placental monocytes are of a maternal rather than fetal genotype [92], suggesting that such placental inflammation may be similar to the inflammation of visceral adipose tissue, an important contributor to metabolic syndrome and cardiovascular disease. In a recent study utilizing a primate model, Japanese macaques who were fed a high-calorie, high-fat diet during pregnancy had significant reduction in uterine volume blood flow, increased placental inflammation and infarctions, and associated higher number of stillbirths [93•].

\section{Assessment of Fetal Well-being}

Given the increased risk for stillbirth, maternal obesity has been proposed as an indication to increase antenatal fetal surveillance, for example, with non-stress tests and assessments of amniotic fluid volume in the third trimester. Indeed, the increased risk for stillbirth associated with obesity is similar to many other risk factors (such as hypertension and diabetes) that are generally accepted as indications for antenatal testing [89••]. Unfortunately, as with most accepted indications for antenatal testing, it remains unproven as to whether such fetal monitoring improves outcomes among obese women [94]. With such a substantial proportion of pregnant women now who are obese, routine testing would consume significant health care resources. With no proven benefit of testing, further risk stratification of obese women based on comorbidities, age, and BMI may be a more prudent approach.

\section{Long-term Outcomes for Offspring}

Although a child's external environment certainly plays an important role in determining the risk for obesity and type 2 diabetes, the in utero environment is increasingly understood as critical in establishing the risk for childhood and adult disease. "Fetal programming" occurs through epigenetic mechanisms, or heritable changes in gene expression that occur independently of changes in the nucleotide sequence. Epigenetic mechanisms, which include chromatin remodeling and DNA methylation, may be heritable across generations $[95,96]$. Early work established intrauterine growth restriction as a risk factor for obesity, metabolic syndrome, type 2 diabetes, and coronary artery disease [97]. Multiple studies have now demonstrated that LGA offspring of obese women and women with gestational and/or type 2 diabetes are also more likely to suffer from these disorders [98-100]. In a longitudinal cohort study of children at age $6,7,9$, or 11 years, Boney et al. found that those who were born LGA to a mother with GDM were at significantly increased risk of metabolic syndrome [98]. The prevalence of at least two components of metabolic syndrome at any of the follow-up time points was $50 \%$ for LGA/GDM children as compared to $29 \%$ for the LGA/non-diabetic group, $21 \%$ for the appropriate-for-gestational age (AGA)/GDM group, and $18 \%$ for the AGA/non-diabetic group. Highlighting the perpetuation of the intergenerational cycle of obesity, a recent study from the Swedish Medical Birth Register demonstrated that women born LGA are more likely to be obese and that their risk of having an LGA offspring themselves increases with their BMI [101•]. The impact of maternal obesity on offspring may not be limited to a long-term risk for obesity 
and metabolic syndrome. Recent data suggest that maternal obesity may increase the risk for neurodevelopment problems in offspring [102••, 103]. In a case-control study, maternal metabolic conditions (including diabetes and obesity) increased the risk for autism in children $2-5$ years of age (OR 1.61, $95 \%$ CI, 1.10-2.37) [102••].

\section{Conclusion}

More than one-third of women are obese and at risk for a wide range of adverse outcomes throughout each pregnancy and across their reproductive lives and beyond. The offspring of obese women are at risk for outcomes such as LGA, which carries the potential for lifelong adverse health consequences and a propagation of risk across generations. Women who develop preeclampsia and gestational diabetes should be counseled that they are at increased long-term risk for cardiovascular disease and type 2 diabetes, respectively [37, 43॰]. The development of these conditions in obese women represents a window into their future health and a "teachable moment" with regard to preventive measures. Clinicians should seize the opportunity to counsel and motivate women with regard to postpartum weight loss and lifestyle modifications that will improve outcomes not only for any future pregnancies, but for themselves and their offspring across their lifespans. Future research should focus on understanding the biological underpinnings of established epidemiological associations such that the most targeted and effective interventions may be implemented for obese women who are pregnant or contemplating pregnancy.

\section{Compliance with Ethics Guidelines}

Conflict of Interest J.R. Chin declares no conflicts of interest. M.A. Murtaugh declares no conflicts of interest.

R. Silver declares no conflicts of interest.

Human and Animal Rights and Informed Consent All studies by R. Silver and J.R. Chin involving animal and/or human subjects were performed after approval by the appropriate institutional review boards. When required, written informed consent was obtained from all participants.

\section{References}

Papers of particular interest, published within the last three years, have been highlighted as:

- Of importance

-• Of major importance

1. Ogden CL, Carroll MD, Kit BK, Flegal KM. Prevalence of obesity among adults: United States, 2011-2012. NCHS Data Brief, No 131 2013. Describes current U.S. obesity trends, with reports stratified by gender and age.
2. Olshansky SJ, Passaro DJ, Hershow RC, Layden J, Carnes BA, Brody $\mathrm{J}$, et al. A potential decline in life expectancy in the United States in the 21st century. N Engl J Med. 2005;352(11):1138-45.

3. Weiss JL, Malone FD, Emig D, Ball RH, Nyberg DA, Comstock $\mathrm{CH}$, et al. Obesity, obstetric complications and cesarean delivery rate-a population-based screening study. Am J Obstet Gynecol. 2004;190(4):1091-7.

4. Metwally M, Ong KJ, Ledger WL, Li TC. Does high body mass index increase the risk of miscarriage after spontaneous and assisted conception? A meta-analysis of the evidence. Fertil Steril. 2008;90(3):714-26.

5. Crane SS, Wojtowycz MA, Dye TD, Aubry RH, Artal R. Association between pre-pregnancy obesity and the risk of cesarean delivery. Obstet Gynecol. 1997;89(2):213-6.

6. Nohr EA, Bech BH, Davies MJ, Frydenberg M, Henriksen TB, Olsen J. Prepregnancy obesity and fetal death: a study within the Danish National Birth Cohort. Obstet Gynecol. 2005;106(2): 250-9.

7. Stothard KJ, Tennant PW, Bell R, Rankin J. Maternal overweight and obesity and the risk of congenital anomalies: a systematic review and meta-analysis. JAMA. 2009;301(6):636-50.

8. Russell A, Gillespie S, Satya S, Gaudet LM. Assessing the accuracy of pregnant women in recalling pre-pregnancy weight and gestational weight gain. J Obstet Gynaecol Can. 2013;35(9):802-9.

9. Cedergren M. Effects of gestational weight gain and body mass index on obstetric outcome in Sweden. Int J Gynaecol Obstet. 2006;93(3):269-74.

10. Nohr EA, Vaeth M, Baker JL, Sorensen T, Olsen J, Rasmussen KM. Combined associations of prepregnancy body mass index and gestational weight gain with the outcome of pregnancy. Am J Clin Nutr. 2008;87(6):1750-9.

11. Institute of Medicine. Weight gain during pregnancy: reexamining the guidelines. 2009.

12. Blomberg M. Maternal and neonatal outcomes among obese women with weight gain below the new Institute of Medicine recommendations. Obstet Gynecol. 2011;117(5):1065-70.

13. Kominiarek MA, Seligman NS, Dolin C, Gao W, Berghella V, Hoffman M, et al. Gestational weight gain and obesity: is 20 pounds too much? Am J Obstet Gynecol. 2013;209(3):214 e211214 e211. Cohort study from the Consortium on Safe Labor indicating that outcomes for obese women may be optimized with GWG less than the 2009 IOM recommendations.

14. Chu SY, Callaghan WM, Bish CL, D'Angelo D. Gestational weight gain by body mass index among US women delivering live births, 2004-2005: fueling future obesity. Am J Obstet Gynecol. 2009;200(3):271. e271-277.

15. Crane JM, White J, Murphy P, Burrage L, Hutchens D. The effect of gestational weight gain by body mass index on maternal and neonatal outcomes. J Obstet Gynaecol Can. 2009;31(1):28-35.

16. Viswanathan M, Siega-Riz AM, Moos MK, et al. Outcomes of maternal weight gain. Evid Rep Technol Assess. 2008.

17. Cohen AK, Chaffee BW, Rehkopf DH, Coyle JR, Abrams B. Excessive gestational weight gain over multiple pregnancies and the prevalence of obesity at age 40. Int J Obes (Lond). 2013.

18. Bastian LA, West NA, Corcoran C, Munger RG. Number of children and the risk of obesity in older women. Prev Med. 2005;40(1):99-104.

19. Robinson WR, Cheng MH, Hoggatt KJ, Sturmer Til, Siega-Riz AM. Childbearing is not associated with young women's longterm obesity risk.

20. Stuebe AM, Oken E, Gillman MW. Associations of diet and physical activity during pregnancy with risk for excessive gestational weight gain. Am J Obstet Gynecol. 2009;201(1):58. e51-58.

21. Muktabhant B, Lumbiganon P, Ngamjarus C, Dowswell T. Interventions for preventing excessive weight gain during pregnancy. Cochrane Database Syst Rev. 2012;4, CD007145. 
22. Villamor E, Cnattingius S. Interpregnancy weight change and risk of adverse pregnancy outcomes: a population-based study. Lancet. 2006;368(9542):1164-70.

23. Chin JR, Krause KM, Ostbye T, Chowdhury N, Lovelady CA, Swamy GK. Gestational weight gain in consecutive pregnancies. Am J Obstet Gynecol. 2010;203(3):279. e271-276.

24. Wise LA, Rothman KJ, Mikkelsen EM, Sorensen HT, Riis A, Hatch EE. An internet-based prospective study of body size and time-to-pregnancy. Hum Reprod. 2010;25(1):253-64.

25. Landres IV, Milki AA, Lathi RB. Karyotype of miscarriages in relation to maternal weight. Hum Reprod. 2010;25(5):1123-6.

26. Jungheim ES, Moley KH. Current knowledge of obesity's effects in the pre- and periconceptional periods and avenues for future research. Am J Obstet Gynecol. 2010;203(6):525-30.

27. Brewer CJ, Balen AH. The adverse effects of obesity on conception and implantation. Reproduction. 2010;140(3):347-64.

28. Rittenberg V, Seshadri S, Sunkara SK, Sobaleva S, Oteng-Ntim E, El-Toukhy T. Effect of body mass index on IVF treatment outcome: an updated systematic review and meta-analysis. Reprod Biomed Online. 2011;23(4):421-39.

29. Styne-Gross A, Elkind-Hirsch K, Scott Jr RT. Obesity does not impact implantation rates or pregnancy outcome in women attempting conception through oocyte donation. Fertil Steril. 2005;83(6):1629-34.

30. Jungheim ES, Schon SB, Schulte MB, Deugarte DA, Fowler SA, Tuuli MG. IVF outcomes in obese donor oocyte recipients: a systematic review and meta-analysis. Hum Reprod. 2013;28(10): 2720-7. Systematic review and meta-analysis indicating that obesity does not affect IVF outcomes among women using donor oocytes. Results not consistent with an endometrial receptivity problem in obese women. However, included studies were generally small and of significant heterogeneity.

31.•• Bellver J, Pellicer A, Garcia-Velasco JA, Ballesteros A, Remohi J, Meseguer M. Obesity reduces uterine receptivity: clinical experience from 9,587 first cycles of ovum donation with normal weight donors. Fertil Steril. 2013;100(4):1050-1058 e1052. Retrospective cohort study found that an increased BMI is associated with decreased implantation, pregnancy, clinical pregnancy, twin pregnan$c y$, and live-birth rates for women undergoing IVF cycles using donor oocytes from normal weight women. Results suggestive of an problem with endometrial receptivity among obese women.

32. Ray JG, Wyatt PR, Vermeulen MJ, Meier C, Cole DE. Greater maternal weight and the ongoing risk of neural tube defects after folic acid flour fortification. Obstet Gynecol. 2005;105(2):261-5.

33. Shaw GM, Velie EM, Schaffer D. Risk of neural tube defect-affected pregnancies among obese women. JAMA. 1996;275(14):1093-6.

34. Werler MM, Louik C, Shapiro S, Mitchell AA. Prepregnant weight in relation to risk of neural tube defects. JAMA. 1996;275(14):1089-92.

35. Racusin D, Stevens B, Campbell G, Aagaard KM. Obesity and the risk and detection of fetal malformations. Semin Perinatol. 2012;36(3):213-21.

36. Dashe JS, McIntire DD, Twickler DM. Maternal obesity limits the ultrasound evaluation of fetal anatomy. J Ultrasound Med. 2009;28(8):1025-30.

37. Dornhorst A, Rossi M. Risk and prevention of type 2 diabetes in women with gestational diabetes. Diabetes Care. 1998;21 Suppl 2: B43-9.

38. Sibai BM, Gordon T, Thom E, Caritis SN, Klebanoff M, McNellis $\mathrm{D}$, et al. Risk factors for preeclampsia in healthy nulliparous women: a prospective multicenter study. The National Institute of Child Health and Human Development Network of Maternal-Fetal Medicine Units. Am J Obstet Gynecol. 1995;172(2 Pt 1):642-8.

39. Hauth JC, Clifton RG, Roberts JM, Myatt L, Spong CY, Leveno $\mathrm{KJ}$, et al. Maternal insulin resistance and preeclampsia. Am J Obstet Gynecol. 2011;204(4):327. e321-326.
40. Saad AF, Kechichian T, Yin H, Sbrana E, Longo M, Wen M, et al. Effects of Pravastatin on Angiogenic and Placental Hypoxic Imbalance in a Mouse Model of Preeclampsia. Reprod Sci. 2013.

41. Fox KA, Longo M, Tamayo E, Kechichian T, Bytautiene E, Hankins GD, et al. Effects of pravastatin on mediators of vascular function in a mouse model of soluble Fms-like tyrosine kinase-1induced preeclampsia. Am J Obstet Gynecol. 2011;205(4):366. e361-365.

42. Girardi G. Can statins prevent pregnancy complications? J Reprod Immunol. 2013. doi:10.1016/j.jri.2013.07.005.

43. Brown MC, Best KE, Pearce MS, Waugh J, Robson SC, Bell R. Cardiovascular disease risk in women with pre-eclampsia: systematic review and meta-analysis. Eur J Epidemiol. 2013;28(1):1-19. Systematic review and meta-analysis finding that women with preeclampsia are at increased future risk of cardiovascular and cerebrovascular disease.

44.• Cnattingius S, Villamor E, Johansson S, Edstedt Bonamy AK, Persson M, Wikstrom AK, et al. Maternal obesity and risk of preterm delivery. JAMA. 2013;309(22):2362-70. Study from the Swedish Medical Birth Register finding that obese women are at increased risk for preterm delivery compared to normal weight women. Analysis stratified by spontaneous preterm delivery and indicated preterm delivery.

45. Ehrenberg HM, Iams JD, Goldenberg RL, Newman RB, Weiner SJ, Sibai BM, et al. Maternal obesity, uterine activity, and the risk of spontaneous preterm birth. Obstet Gynecol. 2009;113(1):48-52.

46. Hendler I, Goldenberg RL, Mercer BM, Iams JD, Meis PJ, Moawad AH, et al. The Preterm Prediction Study: association between maternal body mass index and spontaneous and indicated preterm birth. Am J Obstet Gynecol. 2005;192(3):882-6.

47. Marshall NS, Wong KK, Liu PY, Cullen SR, Knuiman MW, Grunstein RR. Sleep apnea as an independent risk factor for allcause mortality: the Busselton Health Study. Sleep. 2008;31(8): 1079-85.

48. Somers VK, White DP, Amin R, Abraham WT, Costa F, Culebras A, et al. Sleep apnea and cardiovascular disease: an American Heart Association/American College of Cardiology Foundation Scientific Statement from the American Heart Association Council for High Blood Pressure Research Professional Education Committee, Council on Clinical Cardiology, Stroke Council, and Council on Cardiovascular Nursing. J Am Coll Cardiol. 2008;52(8):686-717.

49. Yaggi HK, Concato J, Kernan WN, Lichtman JH, Brass LM, Mohsenin V. Obstructive sleep apnea as a risk factor for stroke and death. N Engl J Med. 2005;353(19):2034-41.

50. Fung AM, Wilson DL, Lappas M, Howard M, Barnes M, O'Donoghue F, et al. Effects of maternal obstructive sleep apnoea on fetal growth: a prospective cohort study. PLoS One. 2013;8(7): e68057.

51. Louis J, Auckley D, Miladinovic B, Shepherd A, Mencin P, Kumar $\mathrm{D}$, et al. Perinatal outcomes associated with obstructive sleep apnea in obese pregnant women. Obstet Gynecol. 2012. Prospective observational study finding that obstructive sleep apnea in pregnant women is associated with increased odds of preeclampsia.

52. Facco FL, Ouyang DW, Zee PC, Grobman WA. Development of a pregnancy-specific screening tool for sleep apnea. J Clin Sleep Med. 2012;8(4):389-94.

53. Hood DD, Dewan DM. Anesthetic and obstetric outcome in morbidly obese parturients. Anesthesiology. 1993;79(6):1210-8.

54. Cedergren MI. Maternal morbid obesity and the risk of adverse pregnancy outcome. Obstet Gynecol. 2004;103(2):219-24.

55. Ovesen P, Rasmussen S, Kesmodel U. Effect of prepregnancy maternal overweight and obesity on pregnancy outcome. Obstet Gynecol. 2011;118(2 Pt 1):305-12.

56. Chu SY, Kim SY, Schmid CH, Dietz PM, Callaghan WM, Lau J, et al. Maternal obesity and risk of cesarean delivery: a metaanalysis. Obes Rev. 2007;8(5):385-94. 
57. Poobalan AS, Aucott LS, Gurung T, Smith WC, Bhattacharya S. Obesity as an independent risk factor for elective and emergency caesarean delivery in nulliparous women-systematic review and meta-analysis of cohort studies. Obes Rev. 2009;10(1):28-35.

58. Sebire NJ, Jolly M, Harris JP, Wadsworth J, Joffe M, Beard RW, et al. Maternal obesity and pregnancy outcome: a study of 287,213 pregnancies in London. Int J Obes Relat Metab Disord. 2001;25(8):1175-82.

59. Denison FC, Price J, Graham C, Wild S, Liston WA. Maternal obesity, length of gestation, risk of postdates pregnancy and spontaneous onset of labour at term. BJOG. 2008;115(6):720-5.

60. Roos N, Sahlin L, Ekman-Ordeberg G, Kieler H, Stephansson O. Maternal risk factors for postterm pregnancy and cesarean delivery following labor induction. Acta Obstet Gynecol Scand. 2010;89(8):1003-10.

61. Vahratian A, Siega-Riz AM, Savitz DA, Zhang J. Maternal prepregnancy overweight and obesity and the risk of cesarean delivery in nulliparous women. Ann Epidemiol. 2005;15(7):467-74.

62.• Kominiarek MA, Vanveldhuisen P, Hibbard J, Landy H, Haberman $\mathrm{S}$, Learman L, et al. The maternal body mass index: a strong association with delivery route. Am J Obstet Gynecol. 2010;203(3): 264 e261-267. Study from the Consortium on Safe Labor finding a dose-dependent relationship between maternal BMI and risk of cesarean section for both nulliparous and multiparous women.

63. Vahratian A, Zhang J, Troendle JF, Savitz DA, Siega-Riz AM. Maternal prepregnancy overweight and obesity and the pattern of labor progression in term nulliparous women. Obstet Gynecol. 2004;104(5 Pt 1):943-51.

64.• Kominiarek MA, Zhang J, Vanveldhuisen P, Troendle J, Beaver J, Hibbard JU. Contemporary labor patterns: the impact of maternal body mass index. Am J Obstet Gynecol. 2011;205(3):244 e241248. Study from the Consortium on Safe Labor reporting modern labor curves and how maternal BMI affects progress in labor, with the first stage being significantly longer for obese women.

65. Landon MB, Leindecker S, Spong CY, Hauth JC, Bloom S, Varner MW, et al. The MFMU Cesarean Registry: factors affecting the success of trial of labor after previous cesarean delivery. Am J Obstet Gynecol. 2005;193(3 Pt 2):1016-23.

66. Zhang J, Bricker L, Wray S, Quenby S. Poor uterine contractility in obese women. BJOG. 2007;114(3):343-8.

67. Higgins CA, Martin W, Anderson L, Blanks AM, Norman JE, McConnachie A, et al. Maternal obesity and its relationship with spontaneous and oxytocin-induced contractility of human myometrium in vitro. Reprod Sci. 2010;17(2):177-85.

68. Chiossi G, Costantine MM, Betancourt A, Hankins GD, Longo M, Saade GR, et al. Effect of maternal body mass index on in vitro response to tocolytics in term myometrium. Am J Obstet Gynecol. 2010;203(3):261. e261-265.

69. Hehir MP, Morrison JJ. The adipokine apelin and human uterine contractility. Am J Obstet Gynecol. 2012;206(4):359. e351-355.

70. Moynihan AT, Hehir MP, Glavey SV, Smith TJ, Morrison JJ. Inhibitory effect of leptin on human uterine contractility in vitro. Am J Obstet Gynecol. 2006;195(2):504-9.

71. Chin JR, Henry E, Holmgren CM, Varner MW, Branch DW. Maternal obesity and contraction strength in the first stage of labor. Am J Obstet Gynecol. 2012;207(2):129. e121-126.

72. Nuthalapaty FS, Rouse DJ, Owen J. The association of maternal weight with cesarean risk, labor duration, and cervical dilation rate during labor induction. Obstet Gynecol. 2004;103(3):452-6.

73. Perlow JH, Morgan MA. Massive maternal obesity and perioperative cesarean morbidity. Am J Obstet Gynecol. 1994;170(2):560-5.

74. Myles TD, Gooch J, Santolaya J. Obesity as an independent risk factor for infectious morbidity in patients who undergo cesarean delivery. Obstet Gynecol. 2002;100(5 Pt 1):959-64.

75. Bates SM, Greer IA, Pabinger I, Sofaer S, Hirsh J. Venous thromboembolism, thrombophilia, antithrombotic therapy, and pregnancy: American College of Chest Physicians EvidenceBased Clinical Practice Guidelines (8th Edition). Chest. 2008;133(6 Suppl):844S-86.

76. Thornburg LL, Linder MA, Durie DE, Walker B, Pressman EK, Glantz JC. Risk factors for wound complications in morbidly obese women undergoing primary cesarean delivery. J Matern Fetal Neonatal Med. 2012;25(9):1544-8.

77. McLean M, Hines R, Polinkovsky M, Stuebe A, Thorp J, Strauss R. Type of skin incision and wound complications in the obese parturient. Am J Perinatol. 2012;29(4):301-6.

78. Santry HP, Gillen DL, Lauderdale DS. Trends in bariatric surgical procedures. JAMA. 2005;294(15):1909-17.

79. Lesko J, Peaceman A. Pregnancy outcomes in women after bariatric surgery compared with obese and morbidly obese controls. Obstet Gynecol. 2012;119(3):547-54. Study finding that women who have undergone bariatric surgery have a decreased risk of GDM but an increased risk of an SGA baby as compared to obese patients who have not undergone bariatric surgery.

80. Richards DS, Miller DK, Goodman GN. Pregnancy after gastric bypass for morbid obesity. J Reprod Med. 1987;32(3):172-6.

81. Weintraub AY, Levy A, Levi I, Mazor M, Wiznitzer A, Sheiner E. Effect of bariatric surgery on pregnancy outcome. Int J Gynaecol Obstet. 2008;103(3):246-51.

82. Kjaer MM, Nilas L. Pregnancy after bariatric surgery-a review of benefits and risks. Acta Obstet Gynecol Scand. 2013;92(3):264-71.

83. Shai D, Shoham-Vardi I, Amsalem D, Silverberg D, Levi I, Sheiner E. Pregnancy outcome of patients following bariatric surgery as compared with obese women: a population-based study. J Matern Fetal Neonatal Med. 2013

84. American Congress of Obstetrics and Gynecology. ACOG practice bulletin no. 105: bariatric surgery and pregnancy. Obstet Gynecol. 2009;113(6):1405-13.

85. Policiano C, Rocha P, Catanho MC, Pinto L, Valentim-Lourenco A, Graca LM. Acute fetal asphyxia after gastric rupture in a pregnant patient with a gastric band. Acta Obstet Gynecol Scand. 2013;92:1419-21.

86. Wax JR, Pinette MG, Cartin A. Roux-en-Y gastric bypassassociated bowel obstruction complicating pregnancy-an obstetrician's map to the clinical minefield. Am J Obstet Gynecol. 2013;208(4):265-71.

87. Renault K, Gyrtrup HJ, Damgaard K, Hedegaard M, Sorensen JL. Pregnant woman with fatal complication after laparoscopic Rouxen-Y gastric bypass. Acta Obstet Gynecol Scand. 2012;91(7):873-5.

88. Stephansson O, Dickman PW, Johansson A, Cnattingius S. Maternal weight, pregnancy weight gain, and the risk of antepartum stillbirth. Am J Obstet Gynecol. 2001;184(3):463-9.

89.• Association between stillbirth and risk factors known at pregnancy confirmation. JAMA. 2011;306(22):2469-2479. Study from the Stillbirth Collaborative Research Network finding that maternal obesity is an independent risk factor for stillbirth.

90. Roberts KA, Riley SC, Reynolds RM, Barr S, Evans M, Statham A, et al. Placental structure and inflammation in pregnancies associated with obesity. Placenta. 2011;32(3):247-54. Maternal obesity is associated with greater placental pro-inflammatory cytokine expression.

91. Challier JC, Basu S, Bintein T, Minium J, Hotmire K, Catalano $\mathrm{PM}$, et al. Obesity in pregnancy stimulates macrophage accumulation and inflammation in the placenta. Placenta. 2008;29(3): 274-81.

92. Basu S, Leahy P, Challier JC, Minium J, Catalano P, Hauguel-de Mouzon S. Molecular phenotype of monocytes at the maternalfetal interface. Am J Obstet Gynecol. 2011;205(3):265. e261-268.

93. Frias AE, Morgan TK, Evans AE, Rasanen J, Oh KY, Thornburg $\mathrm{KL}$, et al. Maternal high-fat diet disturbs uteroplacental hemodynamics and increases the frequency of stillbirth in a nonhuman primate model of excess nutrition. Endocrinology. 2011;152(6): 2456-64. This study utilizing a primate model found that a 
maternal high-fat diet is associated with decreased uterine volume blood flow and increased placental inflammation. Obese animals on the high fat diet had an increased number of stillbirths.

94. American Congress of Obstetrics and Gynecology. ACOG practice bulletin no. 9: Antepartum fetal surveillance. Obstet Gynecol. 94(4).

95. Heerwagen MJ, Miller MR, Barbour LA, Friedman JE. Maternal obesity and fetal metabolic programming: a fertile epigenetic soil. Am J Physiol Regul Integr Comp Physiol. 2010;299(3):R711-22.

96. Aagaard-Tillery KM, Grove K, Bishop J, Ke X, Fu Q, McKnight $\mathrm{R}$, et al. Developmental origins of disease and determinants of chromatin structure: maternal diet modifies the primate fetal epigenome. J Mol Endocrinol. 2008;41(2):91-102.

97. Barker DJ. Maternal nutrition, fetal nutrition, and disease in later life. Nutrition. 1997;13(9):807-13.

98. Boney CM, Verma A, Tucker R, Vohr BR. Metabolic syndrome in childhood: association with birth weight, maternal obesity, and gestational diabetes mellitus. Pediatrics. 2005;115(3):e290-6.

99. Renom Espineira A, Fernandes-Rosa FL, Bueno AC, de Souza $\mathrm{RM}$, Moreira AC, de Castro M, et al. Postnatal growth and cardiometabolic profile in young adults born large for gestational age. Clin Endocrinol (Oxf). 2011;75(3):335-41.

100. Desai M, Beall M, Ross MG. Developmental origins of obesity: programmed adipogenesis. Curr Diab Rep. 2013;13(1):27-33.

101. Cnattingius S, Villamor E, Lagerros YT, Wikstrom AK, Granath F. High birth weight and obesity-a vicious circle across generations. Int J Obes (Lond). 2012;36(10):1320-4. This study from the Swedish Medical Birth Register examines how both a mother's own birthweight and adult body weight contribute to the risk of her having an LGA baby.

102.• Krakowiak P, Walker CK, Bremer AA, et al. Maternal metabolic conditions and risk for autism and other neurodevelopmental disorders. Pediatrics. 2012;129(5):e1121-8. Case-control study finding that maternal metabolic conditions such as obesity and diabetes are associated with greater odds of autism and other neurodevelopmental problems in children.

103. Dodds L, Fell DB, Shea SB, Armson BA, Allen AC, Bryson S. The role of prenatal, obstetric, and neonatal factors in the development of autism. J Autism Dev Disord. 2011;41(7):891-902. 